\title{
Application of communities of practice in managing tacit knowledge in higher learning institutions: Sokoine University of Agriculture, Tanzania
}

\author{
Edda T. Lwoga and Wanyenda L. Chilimo \\ Sokoine University of Agriculture, P. O. Box 3022, Morogoro, Tanzania. \\ wchilimo@yahoo.com, tandib19@yahoo.com
}

\begin{abstract}
Universities and other higher learning institutions are recognized to be in the knowledge business because they are involved in knowledge creation, dissemination and learning. However, in recent years knowledge has gained increasing economic importance and therefore the role of knowledge management and communities of practice for knowledge creation, sharing and utilization in higher learning institution is becoming crucial. This paper discusses the application of Communities of Practice (CoP) as a means of capturing and sharing organizational knowledge in higher learning institutions. CoPs are informal networks that enable professionals to develop a shared meaning, engage in knowledge building and help to stimulate knowledge flow among the members. Effectively cultivated CoPs can be an important strategy for tapping and harnessing tacit knowledge and facilitating knowledge sharing. This paper draws on an extensive literature review and on various case studies that deal with the concept of communities of practice. The paper discusses the postulation as to how CoPs can be used for harnessing tacit knowledge in higher learning institutions. Relevant theories with regard to CoPs are also highlighted, and applied in practice at the Sokoine University of Agriculture (SUA) in Tanzania as a case study. Lastly, the paper give recommendations on how best CoPs can be implemented in managing tacit knowledge in higher learning institutions, especially in Africa.
\end{abstract}

\section{Introduction}

Ever since their inception, universities have been inherently practicing knowledge management by storing, accessing, and delivering knowledge in some manner (Wiig, 1997: 7; Reid, 2005). However, in recent years knowledge has joined the ranks in being seen as a driver of economic growth and a driving force behind the current knowledge-based economy which places great importance on the use of information and knowledge, as well as its 
creation and sharing (World Bank, 1998; van den Berg and Snyman, 2003: 1; Davenport and Pruask, 1998: vii-viii).

Many organizations including higher learning institutions have begun to adopt knowledge management practices in order to capitalize on knowledge as an asset and to derive the needed values from it. Knowledge in organizations can be explicit and recorded, or can be tacit, that is in people's minds, learnt by experience and often communicated indirectly (Wenger, McDermott and Snyder, 2002: 9; Branin, 2003; Claire, 2002: 1011). Many universities have been harnessing its creation, dissemination, organization, recording and retrieval of explicit knowledge since their inception. However, a large proportion of tacit knowledge has never been recorded, documented or captured because it is difficult to harness and it is not seen as a revenue-earning product or commodity.

Communities of Practice (CoP) if effectively cultivated can be an important strategy for tapping and harnessing tacit knowledge and making it sharable throughout the organization, hence improving organizational effectiveness. A CoP normally constitutes a group of practitioners who share a common interest or passion in an area of competence and are willing to share the experiences of their practice (Wenger, McDermott and Snyder, 2002: 4; Davenport and Pruask, 1998: 38). These communities can be used as the first knowledge management activity in a university setting due to their ability to produce an impact within a short period of time, with a high success rate and at a relatively low cost to implement, which will then act as an encouragement for the wider implementation of knowledge management. Furthermore, CoPs are vital because they provide professional relationships and social ties which according to Cappelli (2000: 104) and Cohen and Prusak (2001: 19) constitute one of the important reasons why people stay with a company.

The concept of CoP has recently gained importance, both in the business and the academic world, and there are various theories that explain this concept, of which this paper will accentuate and conceptualize them in the context of higher learning institutions, especially in Africa. 


\section{Conceptualizing Knowledge Management (KM) and Communities of Practice (CoP)}

Davenport and Prusak (1998:5) defined knowledge as a fluid mix of framed experience, values, contextual information, and expert insight that provide a framework for evaluating and incorporating new experience and information. In organizations, it often becomes embedded not only in documents and repositories but also in organizational routines, processes, practices, and norms. Knowledge is increasingly seen as central to the success of organizations and an asset that needs to be managed.

$\mathrm{KM}$ is therefore defined as the process of capturing, organizing, and storing knowledge and experiences of individual workers and groups within an organization and making this information available to others in the organization. It involves the distribution, access and retrieval of unstructured information about human experiences between interdependent individuals or among members of a work group. Claire (2002: 1014) asserted that in simple language KM is an effort to increase useful knowledge within the organization. Furthermore, Branin (2003) explained that KM is not concerned so much with the data or information but rather with active management and support of the expertise and knowledge that exists in people and much of this kind of knowledge is tacit rather than explicit.

Knowledge is mainly put into two categories, explicit and tacit knowledge. Explicit knowledge includes the knowledge that has been codified in documents such as databases and web pages. It is knowledge that has been explained, recorded, or documented (Branin, 2003). However, tacit knowledge is the wealth of know-how and skills that resides in people's minds, deeply rooted in their life experience and learning and is shown through behaviour or performance. Tacit knowledge includes know-how, skills and expertise, thinking, experiences, heuristics or rules of thumb, habits, culture, undocumented history, and ways of thinking. Wenger, McDermott and Snyder (2002: 9); Davenport and Pruask, (1998b: 70) further explain that the tacit aspect of knowledge is often the most valuable one and consists of embodied expertise, a deep understanding of complex, interdependent systems that enables dynamic responses to context-specific problems. 
In explaining further the differences between explicit and tacit knowledge (Claire, 2002: 1011) made the following distinctions.

Explicit knowledge Tacit knowledge

Formally articulated _ - Difficult to articulate or unspoken

Documented $\quad$ - $\quad$ Transferred through conversations

Stored in repositories - $\quad$ Held within self, personal

Reports, lesson learnt-Insight and understanding

Fixed, codified $\quad$ - Judgments, assumptions

However, the explicit/tacit distinction of knowledge is structural and relational which applies to the thinking processes of the individual. The tacit/explicit distinction is merely used to describe a relation between kinds of knowledge (Mooradian, 2005: 107). In a real sense explicit knowledge depends on tacit knowledge and for any explicit knowledge, there must be some tacit knowledge. Furthermore, explicit knowledge is an extension or projection of tacit knowledge to a new level or awareness and it is a useful way to understand how knowledge moves from the personal to the organizational (Claire, 2002: 1013).

CoPs constitute groups of people who share a concern, a set of problems, or a passion about a topic, and who deepen their knowledge and expertise in this area by interacting on an ongoing basis (Wenger, McDermott and Snyder, 2002: 4). These communities arise naturally, operate ubiquitously, often invisibly, in a wide variety of organizations, and have been in existence from the very beginning of human civilization. CoPs are informal networks that support professional practitioners to develop shared meanings, engage in knowledge building and help stimulate knowledge flow among the members.

Different names are sometimes used to describe these informal networks. Some of these include communities of interest, knowledge networks (Davenport and Pruask, 1998: viii), 
communities of ideas (Engel, 1997: 239), thematic networks, virtual teams and virtual knowledge communities (Cummings and van Zee, 2005: 7). It is in these communities that individuals develop the capacity to create, refine, share and eventually apply knowledge.

Brown and Gray (1998) further explained that CoPs are small groups of people who have worked together over a period of time. They are not a team, not a task force, not necessarily an authorized or identified group or a formal structure like departmental project teams. They are informal entities existing in the minds of the members and glued together by a shared interest or problem. What holds them together is a common sense of purpose and a real need to know what each other knows. Van den Berg and Snyman (2003: 1) asserted that a CoP is different from a team because it is defined by a topic of interest, not by a task it has to accomplish.

CoPs are nodes for the exchange and interpretation of information and knowledge. Because members have a shared understanding, they know what is relevant to communicate and how to present information in useful ways. As a consequence, CoPs are an ideal channel for moving information, such as best practices, tips, or feedback, across organizational boundaries. Wenger, McDermott and Snyder (2002: 6) observe that cultivating communities of practice in strategic areas of an organization or an institution is a practical way to manage knowledge as an asset.

Therefore, higher learning institutions need to take a full advantage of CoPs which in most cases already exist around various areas of competences in these institutions. CoPs are mainly self-organizational, although there has to be a certain measure of facilitation, encouragement and management in the manner in which knowledge is created, shared and applied, even if it is only to ensure a supportive environment. Higher learning institutions can create an environment in which CoPs prosper by valuing the learning they do, making time and other resources available for their work, encouraging participation and removing barriers. Wenger, McDermott and Snyder (2002: 13) note that if an institution or organization fails to take 
active steps to cultivate CoPs, these communities will still exist, but they are unlikely to achieve their full potential.

\section{Theories of communities of practice}

Two theories of communities of practice are discussed below. These include the situated learning theory and the social capital theory. The term community of practice was first coined by Lave and Wenger (1991) who also created the model of situated learning which proposes that learning, involves a process of engagement in a 'community of practice' which facilitates social engagement and provides the proper context for learning to take place (Lave and Wenger, 1991: 14). According to this model learning involves participation in a community of practice and in this case participation refers to the process of being an active participant in the practices of social communities and being actively involved in constructing identities and generating meaning in relation to these communities (Wenger. 1998: 4).

Lave and Wenger (1991: 29) described a CoP as a set of relations among persons, activities, and the world over time and in relation to other peripheral and overlapping CoPs. They saw the learning that took place in such communities not as narrowly situated learning, where instances of practice are simply replicated, but learning taking place in three dimensions which is described as legitimate peripheral participation (Lave and Wenger, 1991: 108-9). These dimensions provide a way to speak about the relations between newcomers and oldtimers, and about activities, identities, artifacts, and communities of knowledge and practice.

Legitimation is the dimension of CoPs that is concerned with power and authority relations in the group. Legitimacy in a CoP can be formal, such as following the hierarchy and rank that individuals have in an organization or in a community of practice or it can also be informal, depending on the type of $\mathrm{CoP}$ and activities involved. The terms peripheral and full participation are used to denote the degree of engagement with and participation in the community but also peripheral participation is connected to issues of legitimacy of the social 
organization and control over resources. The term participation is used to imply participation in an activity of which all participants have a common understanding of what it means for their lives and the community. Wenger (1998:76-85) explains further that in order for practice to generate coherence within a community, the essential characteristics of mutual engagement, shared repertoire, and joint enterprise must be present.

Social capital can be defined as the sum of the actual and potential resources embedded within, available through, and derived from the network of relationships possessed by an individual or social unit (Nahapiet and Sumantra, 1998: 242). These social resources include common identity, familiarity, trust, and a degree of shared language and context among individuals. Much like financial or human capital, social capital can be fostered and tapped as needed to enable individuals to perform their jobs more efficiently and effectively. Communities of practice are valuable to organizations because they contribute to the development of social capital, which in turn is a necessary condition for knowledge creation, sharing and use.

\section{CoP and management of tacit knowledge in higher learning institutions}

Higher learning institutions have significant opportunities to apply knowledge management practices to support every part of their mission, explained Kidwell et al (2001: 24). In the corporate sector $\mathrm{KM}$ is mainly used to connect people with the knowledge that they need to take action and is considered as a key to achieving breakthrough competitive advantage. Applying knowledge management techniques in higher learning institutions, especially those techniques that aim at managing tacit knowledge, is vital as it is in the corporate sector. This is important because tacit knowledge has been described as the critical source of innovation (Nonaka and Takeuchi, 1995: 20-55) and the basis of competitive advantage (Danskin et al., 2005:91).

Effective management of tacit knowledge in higher learning institutions can lead to better decision-making capabilities, reduced "product" development cycle time (for instance in 
curriculum development and research), improved academic and administrative services, and reduced costs (Kidwell et al., 2001: 2). Furthermore, the competitive pressures higher learning institutions are now experiencing, resulting from the reduction in government financial support and the consequent need for enterprising approaches to revenue generation, bring a commercial orientation to the provision of teaching and student services. This causes higher learning institutions and universities to regard their teaching programmes, at least to some extent, as a market commodity which is aimed at meeting the needs of the customer (Reid, 2005) and therefore, needing to apply KM to achieve the competitive advantage as in corporate sector.

In addition, KM applications could benefit a number of university processes and services such as the research and curriculum development process, student alumni services and administrative services and strategic planning. Each university has some staff members who are experts or possess some knowledge or connections which are vital to the university, for instance a faculty member who has led a task force for curriculum revision successfully. Relying on the institutional knowledge of unique individuals can hamper the flexibility and responsiveness of any organization. The challenge is to convert the information that currently resides in those individuals and make it widely and easily available to any faculty member, staff, or other constituent. An institution-wide approach to KM can lead to exponential improvements in sharing knowledge, both explicit and tacit, and subsequent surge benefits.

One of the strategies which can be used for managing tacit knowledge in the university setting is the use of CoPs which can be used as a way of helping faculty members and other staff of the university to share tacit knowledge through talking about their specific experiences. CoPs are important to the functioning of any organization, but they become crucial to those that recognize knowledge as a key asset. From this perspective, an effective university or any other institution of higher learning should comprise a constellation of interconnected CoPs, each dealing with specific aspects of the institution's competency, from the administrative work of the university to the management of research activities. Knowledge is created, shared, organized, revised, and passed on within and among these communities. 
Noriko and Kling (2002) urged that CoPs are being recognized as groups within which the sharing of tacit knowledge takes place and therefore it is important that they are supported if $\mathrm{KM}$ is to move beyond the established practices of capturing and codifying explicit knowledge. This is important because most organizations' competitive advantage is embedded in the intangible, tacit knowledge of its workers and the stories they can tell.

Academicians with a common interest have been forming networks and groups for collaboration for years. Therefore, the same groups could also be formed in all the different functions and aspects of the university. Milam (2001) asserted that it is with knowledge management that institutions of higher learning will be better able to increase student retention and graduation rates, retain a technology workforce in the face of severe employee shortages, expand new web-based offerings, work to analyze the cost-effective use of technology to enable higher enrollment, transform existing transaction-based systems to provide information, not just data, for management, and compete in an environment where institutions within the country and across national borders meet students' needs at any time and anywhere.

\section{Applying CoP at Sokoine University of Agriculture}

Many universities and higher learning institutions especially in Africa have not yet clearly embraced the concept of communities of practice for management of organizational knowledge especially tacit knowledge. These communities exist in these institutions but no efforts are being made to make them functional and they are not recognized as important elements for knowledge creation, sharing and utilization. According to Wenger, McDermott and Snyder (2002: 4) CoPs already exist within organizations. The fundamental question is whether or not CoPs can actually be “cultivated" to enhance organizational knowledge and performance. Given the social and dynamic dimensions of knowledge generation and transmission, managers are encouraged to carefully consider the social structures that can foster knowledge development and learning within and across organizations using the CoPs. Management in organizations also need to offer a useful framework, concrete examples, and 
sensible design principles for identifying, facilitating, and sustaining communities of practice within and across organizations.

In a study that investigated the application of CoPs in the corporate environment in South Africa, van den Berg and Snyman (200) found out that CoPs contributed to the successful capturing and sharing of organizational knowledge. Through CoPs employees became more aware of the value of knowledge. Likewise the same results were found in several communities such as C3NET and organizations such as Ben \& Jerry's, Shell Oil Company, Hewlett-Packard (Wenger McDermott and Snyder, 2002: 65-68), Xerox, Exxon, and IBM (van den Berg and Snyman, 2003).

In another study a knowledge management initiative was introduced in the Pepperdine University's Educational Technology (EdTech) doctoral programme in the USA. This knowledge management initiative involved the implementation of group memory technology, in an attempt to cultivate a community of practice so as to capture and transfer the knowledge being generated by participants engaging in the EdTech doctoral programme. This study found out that implementation of KM can be done more successfully if a CoP is in place, and understanding the key characteristics of a CoP is imperative for successful knowledge management (Adam and Freeman, 2000: 43). A study by Mngadi (2007) found out that communities of practice contribute to the management of tacit knowledge at the Faculties of Humanities of the University of KwaZulu-Natal and the University of Zululand in South Africa.

At Sokoine University of Agriculture (SUA) in Tanzania as is the case of many other universities in Africa the concept of knowledge management and cultivating communities of practice has not yet been fully embraced. SUA is a reputed university in Africa dealing with the disciplines of agriculture and related fields. Currently the university has four faculties, which are the faculty of agriculture, faculty of forestry, faculty of veterinary medicine and faculty of science. Each of these faculties has several departments. The university has more that 200 academic staff and offers a range of agricultural related degree programmes at the undergraduate and postgraduate level. 
There are several communities of practice within the university whereby staff members are linked together with one another, based on the different types of activities they are doing such as research, teaching and learning, consultancy assignments and administrative work. However, the university management does not recognize and nurture these communities due to many factors, but mainly because lack of awareness about the whole concept of CoP, and even the application of CoP theories and concepts is still minimal.

Lack of awareness of knowledge management and communities of practice concepts in higher learning institutions presents a challenge to librarians and information professionals in these institutions. Davenport, T. H. and Prusak, L. (1998: 30) observe that in many institutions and in the corporate sector librarians frequently act as covert knowledge brokers, suited by temperament and their role as information guides. In the course of their work these information professionals come to understand a great deal about the various knowledge needs and resources of the institutions. Given the above, librarians need to take an active role in raising awareness about KM issues and even to take part in the actual implementation of these concepts.

In a study that analyzed grassroots knowledge management initiatives Delio (2000) found out that most of the companies that were implementing KM do it at the grassroots level. Delio (2000) further explained that even when there was support from top management for a project, the KM leader was "not a top dog in the organization." Therefore the information professional at SUA and other institutions with similar problems can take the position of KM leaders in their institutions and they can also play an advocacy role in raising awareness of these concepts in their institutions.

However, in order for these professionals to take this position they also need to be informed and keep themselves updated by adopting the strategy of lifelong learning about such new subjects through reading, attending seminars and workshops and taking advantage of the available e-learning opportunities. Furthermore, in order for these concepts to bring the required benefits it is high time that this subject is included in the library school curricula. In 
the case of Tanzania, knowledge management is not taught anywhere in all the available library schools and even other related professions.

At SUA other forms of communities of practice activities are being made possible by using the internet which has opened up new avenues with regard to the facilitation of CoPs at SUA that has led to the emergence of activities such as online discussion groups, web logs and instant messaging. Other supporting technologies that are used for CoPs at SUA include telephones, fax machines and e-mail. Online discussion groups enable staff members of SUA to communicate with each other. About 45 academic staff members of the university subscribe to this listserv in order to share information and the traffic on the listserv is relatively heavy. The listserv involves experienced academic staff and professors and relatively junior academic members of staff. This listserv helps the university community to exchange knowledge in terms of solving problems, making announcements, brainstorming, generating ideas etc. However, at present, only a small number of academicians participate in the SUA discussion group because the group is still new. The former discussion group which was hosted by the university intranet crashed due to some technological problems and unfortunately members have been slow to move to the new discussion group which is being hosted by Yahoo.

Staff members at SUA are however not confined to one professional CoP but can exchange knowledge with other academicians and researchers in their field, for example the Tanzania Library Association discussion group, e-think-tank (to exchange knowledge about ICTs) and, Aginfo-tz (i.e. to exchange agricultural information among librarians). Similar groups are also available in various disciplines such as veterinary medicine and forestry.

Staff members at SUA are also involved in CoPs through informal face-to-face meetings such as:

- Kick-off meetings or during coffee/tea and lunch breaks 
- Informal departmental and faculty meetings. For example, if any member has attended a conference, they normally meet so that the member can inform others about the lessons learnt from the conference

- Members' directory, although not in electronic format, has been helping the university community to extract some new knowledge

- Project collaboration, where researchers meet, brainstorms and share knowledge about the project.

The CoP theories have great potential for the creation and sharing of organizational knowledge in higher learning institutions. However, these theories can also be applied in teaching and learning in a university setting. Many universities in Africa are currently embracing e-learning and the creation of online learners' communities using information and communication technologies. The theory of situated learning by Lave and Wenger (1991: 14) views learning as an act of membership in a community of practice. This concept can also be used to enhance students' learning especially in an e-learning environment.

E-learning is one of the most important KM practices and something which one would expect higher education institutions to have as an advantage (Milam, 2001). Knowledge is often built up and generated by small, informal, self-organizing networks of practitioners. Therefore, the online learning communities made possible by the e-learning platforms create new settings in which people can communicate and share their knowledge across both geographical and temporal boundaries. Such communities are regarded as models for dynamic, productive knowledge creation and sharing in education (Ubon and Kimble, 2002). In this case learning is not just considered as the result of teaching but also as a result of being actively involved and participating in a CoP.

Furthermore, higher learning institutions can utilize these e-learning opportunities not just for students as online customers, but these platforms can also be used by the academicians and other employees of these institutions as part of capitalizing on their knowledge as an intellectual asset. The implementation of e-learning at SUA is at the initial stage. This is being developed using Moodle - a course management system based on free and open source 
software. This system is expected to enable students to exchange information and knowledge among themselves and also with their lecturers. The system has discussion forums, chat rooms and features for lecturers to upload learning materials and meet with their students virtually.

Data has revealed that some forms of CoP activities at SUA do exist. However, efforts need to be made to cultivate and nurture these communities so as to make them more effective in the sharing of tacit knowledge, thereby enhancing the effectiveness of the institution and making it more competitive.

\section{Conclusion}

CoPs are naturally present in all organizations. However, for these communities to exploit the type of social capital required to effectively create, share and use organizational knowledge, they often require outside investment and facilitation from the parent institution. Higher learning institutions need to become proactive and systematic about cultivating CoPs and integrating them into the institutional strategies for the benefit of the institutions as well as for the benefit of the members and communities themselves.

\section{Recommendations}

The paper recommends the following.

First, information professionals in higher learning institutions should play a leading advocacy role in raising awareness of the importance of communities of practice and even in the actual implementation of these concepts.

Second, higher learning institutions operate in an environment which is constantly changing; therefore, to be effective new management tools and strategies which aim at effective utilization of the intellectual assets of these institutions are required.

Third, higher learning institutions in Africa should nurture people networks and provide a conducive environment for CoPs to emerge, foster the formalization of the community, and 
plan activities to help grow and sustain these communities. The management should also assist people to feel safe in connecting and expanding their personal networks. CoPs are dynamic social structures that emerge naturally but they need to be cultivated and nurtured for them to be effective in knowledge sharing.

\section{References}

Adams, E. C. and Freeman, C. (2000). "Communities of practice: bridging technology and knowledge assessment.” Journal of Knowledge Management, 4 (1), 38-44.

Branin, J. J. (2003). Knowledge management in academic libraries: building the knowledge bank at the Ohio State University. [Online] https://kb.osu.edu/dspace/bitstream/1811/187/1/KBJAL.pdf. (Accessed $5^{\text {th }}$ November 2005).

Brown, J. S., and Gray, E. S. (1998). The people are the company. [Online] $<$ http://www.fastcompany.com/online/01/people.html $>$ (Accessed 25 ${ }^{\text {th }}$ August 2005).

Claire, M. (2002). "Knowledge management and the dynamic nature of knowledge." Journal of the American Society for Information Science and Technology, 53 (12), 1009-1018.

Cappelli, P. (2000). “A market-driven approach to retaining talent,” Harvard Business Review, January-February: 103-111.

Cohen, D. and Prusak, L. (2001). In good company: how social capital makes organizations work. Boston: Harvard Business School Press.

Cummings, S. and A. van Zee, (2005). "Communities of practice and networks: reviewing two perspectives on social learning.” KM4D Journal, 1 (1), 6-21. [Online] $<$ www.km4dev.org/journal $>$ (Accessed $10^{\text {th }}$ January 2006).

Delio, M. (2000). “Grassroots are greener; knowledge initiatives advances from Bottom-up successes, not by executive fiat,” Knowledge Management, 3 (2), 47-50. [Online] http://www.destinationcrm.com/km/dcrm_km_article.asp?id=170 (Accessed $10^{\text {th }}$ January 2006).

Danskin, P. Englis, B. G. Solomon, M. R. Goldsmith, M. Davey, J. (2005). "Knowledge management as a competitive advantage: lessons from the textile and apparel value chain," Journal of Knowledge Management, 9 (2), 91-102. Davenport, T. H. and Prusak, L. (1998). Working knowledge: how organizations manage what they know. Boston: Harvard Business School Press.

Engel, P.G.H. (1997). The social organisation of innovation, a focus on stakeholder 
Interaction. Amsterdam: Royal Tropical Institute.

Kidwell, J. J. Linde, V., Karen, M. and Sandra, L. J. (2001). “Applying corporate knowledge management practices in higher education.” In Gerald, B. (ed.) Information alchemy; the art and science of knowledge management. EDUCAUSE Leadership Series \#3. San Francisco: Jossey-Bass: 1-24

Lave, J. and Wenger, E. (1991). Situated learning: legitimate peripheral participation. Cambridge: Cambridge University Press.

Mngadi, B.P. (2007). Communities of practice in institutions of higher learning: a descriptive study of the humanities at the University of KwaZulu-Natal and the University of Zululand. Masters Thesis. Pietermaritzburg: University of KwaZulu-Natal.

Milam, J. H. (2001). Knowledge management for higher education. ERIC Digest.

[Online] < http://www.ericdigests.org/2003-1/higher.htm $>$ (Accessed 10 ${ }^{\text {th }}$ January 2006).

Mooradian, N. (2005). “Tacit knowledge: philosophic roots and role in KM.” Journal of Knowledge Management, 9 (6), 104-113.

Nahapiet, J. and Sumantra, G. (1998). "Social capital, intellectual capital and the organizational advantage.” Academy of Management Review, 23, 242-266.

Nonaka, I. and Takeuchi, H. (1995). The knowledge - creating company: how Japanese companies create the dynamics of innovation. New York: Oxford University Press.

Noriko, H. and Kling, R. (2002). IT supports for communities of practice: an empirically-based framework. Center for Social Informatics working paper No. WP- 02-02. [Online] < http://rkcsi.indiana.edu/archive/CSI/WP/WP02-02B.html $>$ (Accessed $10^{\text {th }}$ November 2005).

Reid, I. C. (2005). The web, knowledge management and universities. [Online] < http://ausweb.scu.edu.au/aw2k/papers/reid/paper.html $>$ (Accessed $10^{\text {th }}$ January 2006).

Ubon, A, N. and Kimble, C. (2002). Knowledge management in online distance education. [Online] < http://www.cs.york.ac.uk/mis/docs/km_in_olde.pdf.> (Accessed $2^{\text {nd }}$ November 2005).

Van den Berg H. and Snyman M. M. M. (2003). "Managing tacit knowledge in the corporate environment: communities of practice." South African Journal of Information Management, 5 (4). [Online] <http://www.sajim.co.za/default.asp?to=peer3vol5nr4> (Accessed 10 ${ }^{\text {th }}$ November 2005). 
Wenger, E. (1998). Communities of Practice. Learning as a social system: systems thinker. [Online] <http://www.co-i-l.com/coil/knowledge-garden/cop/lss.shtml > (Accessed 30 December 2004).

Wenger, E., McDermott, R. and Snyder, W. M. (2002). Cultivating communities of practice: a guide to managing knowledge. Boston: Harvard Business School Press.

Wenger, E. (1998). “Communities of practice: learning as a social system.” The Systems Thinker. 9(5). Pegasus Communications Inc., Waltham, MA, USA.

Wiig K. M., (1997). “Knowledge management: an introduction and perspective.” Journal of Knowledge Management, 1 (1), 6-14.

World Bank. (1998). World Development Report 1998/1999: knowledge for development. Oxford: Oxford University Press. [Online]

< $\underline{\text { http://www.worldbank.org/wdr/wdr98/overview.pdf }}>$ (Accessed 18 ${ }^{\text {th }}$ May 2005). 